\title{
Internal and external validity of the experiences in close relationships questionnaire in an american and two dutch samples
}

\author{
Henk Jan Conradi* \\ Coby Gerlsma*^ \\ Marijtje van Duijn $n^{\star * *}$ \\ Peter de Jonge ${ }^{\star, \star \star \star \star}$
}

* Department of Psychiatry, University Medical Center Groningen, University of Groningen, the Netherlands

** Department of Clinical and Developmental Psychology, University of Groningen, the Netherlands

*** Department of Sociology, Interuniversity Graduate School for Psychometrics and Sociometrics, University of Groningen, the Netherlands

Department of Internal Medicine, University Medical Center Groningen, University of Groningen, the Netherlands

THE NETHERLANDS

ABSTRACT - Background and objectives: The Experiences in Close Relationships scale (ECR) is much used in adult attachment research. In this study we examined: the psychometric properties of the Dutch ECR in comparison with the original American ECR; the claim of orthogonality of its scales Avoidance and Anxiety; and a broader applicability of the ECR, because much research is restricted to psychology student samples.

Methods: In Study 1 we investigated the ECR's internal structure by means of confirmative factor analysis in the American psychology student sample in which the ECR was originally validated. We compared these findings with the results of factor analyses in: a Dutch psychology student sample to test whether the Dutch translation yields comparable results; and a Dutch general population sample to evaluate the supposed orthogonality and to determine a broader applicability of the ECR. In Study 2 we evaluated aspects of the external validity of the ECR.

Results: Confirmative factor analysis supports the original two factor structure in both Dutch samples, although less clear in the population sample. As opposed to both student 
samples the scales correlate moderately in the population sample. Results support external validity of the ECR in both Dutch samples.

Conclusions: Since the supposed orthogonality of the scales varies by sample, the internal validity of the (Dutch) ECR varies by sample as well, namely from satisfactorily (population) to adequate (students). The external validity of the Dutch ECR is compared to the American version adequate, suggesting a broader applicability.

Received 5 May 2006

Accepted 27 July 2006

\section{General introduction}

Ever since Bowlby postulated insecure infant-caregiver attachment as a vulnerability factor in the development of psychopathology $^{1,2,3,4}$, researchers have been trying to capture the attachment construct in various theories and measurement methods. Two research traditions are discernable: research on infantcaregiver attachment, of which Ainsworth and Main are important representatives, and the adult attachment tradition. The latter started with Hazan and Shaver who broadened the attachment concept by rephrasing Ainsworth's original threefold typology of infant-caregiver attachment and applied it to current adult romantic relationships ${ }^{5}$. After that, a bewildering variety of adult attachment typologies, adult attachment-related constructs, and measurement instruments, like numerous self-reports, were developed ${ }^{6}$.

Amidst of this diversity Bartholomew returned to Bowlby's original conceptualization of two working models which were supposed to underlie adult attachment. The two dimensional working models are: (1) model of self, or one's expectation of being perceived by attachment figures as acceptable or lovable; and (2) model of other, or a person's expectation of the accessibility and responsiveness of attachment figures to one's needs. Based on the logical combination of these two bi-polar working models, she criticized Hazan and Shaver's threefold typology and instead proposed four attachment prototypes ${ }^{7,8,9}$. These are: Secure (positive models of self and other), Preoccupied (negative model of self and positive model of other), Dismissing (positive model of self and negative model of other), and Fearful (negative models of self and other).

In these years empirical support emerged for the existence of the fundamental bidimensional structure underlying attachment from analyses of data from both the infant-caregiver attachment ${ }^{10}$, as well as the adult attachment tradition ${ }^{11}$. Brennan and colleagues collected all adult attachment self-report scales (60) known at that time. The constituting items (482 in total, reduced to 323 by omitting the redundant ones) were administered to 1,086 psychology students. Factor analysis resulted in two factors, each consisting of the 18 highest loading items, namely Avoidance of intimacy (or discomfort with closeness), and Anxiety about rejection or abandonment (associated with jealousy and preoccupation with attachment). These form the subscales of the Experiences in Close Relationships (ECR) questionnaire; which in combination can yield the four attachment clusters as proposed by Bartholomew. The two dimensions can be interpreted as cognitive attachment-related representations or working models, like Bartholomew does. Others however, interpret the dimensions more 
closely to the content of the items as emotional and behavioral attachment-related regulation components ${ }^{12}$. Brennan et al. ${ }^{11}$ suppose that the two dimensions are in essence orthogonal or uncorrelated. However, the empirical support of that claim was restricted to their student sample.

Since the ECR is both conceptually (the bi-dimensional structure) and empirically (based on a factor analysis of all known self-report items) a promising questionnaire, we translated, adapted and empirically investigated the ECR for research goals in Dutch speaking communities. Because we think there is no principal reason why Anxiety and Avoidance should be uncorrelated, and because we wanted to determine a broader applicability, we evaluated the ECR in a student and a general population sample. In Study 1 we tried to replicate the two factor structure of the ECR and examined the supposed orthogonality. In Study 2 we evaluated aspects of the external validity.

\section{Study 1: Internal validity}

\section{Introduction Study 1}

To evaluate the internal structure of the ECR we applied confirmative factor analysis to test if we were able to replicate the two factor structure of the ECR. Next we computed the internal consistencies and intercorrelations of the subscales. We used three samples: (1) Brennan's original psychology student sample as benchmark; (2) a Dutch psychology student sample; and (3) a Dutch general population sample. Comparison of the results of the analyses in both psychology student samples will give us information on the quality of the Dutch translation of the ECR. To determine a broader applicability and to investigate the claim of orthogonality of the scales, we compared the findings of the analyses from both psychology student samples with the general population sample. This is necessary because: (1) too much research with the ECR is restricted to socially homogeneous convenience samples of psychology students, while this group is from a clinical perspective of very limited value compared to a socially more heterogeneous population sample; and (2) we suspect that students represent adolescent rather than adult attachment, because students are in the midst of their identity development and lack experience with lasting relationships.

\section{Method Study 1}

\section{Respondents}

Both the American and Dutch psychology students received research credits for participating in the study. Their answers were treated completely anonymous. The Dutch psychology student sample consisted of two subsamples; approximately half of them earned their credits in 2002 and the other half in 2003. In order to obtain a sample from the Dutch general population, we randomly selected 1,000 people from telephone books covering the four northern provinces in the Netherlands and sent them a booklet containing several questionnaires (185 items in total) and a letter stating that the completed tests would be treated anonymously. We asked them to complete the questionnaires on their own. A reminder followed after three weeks.

\section{Measurement instrument}

The ECR is developed to measure adult attachment within romantic relationships in past and present. Internal consistencies of Anxiety and Avoidance are .91 and .94 resp. ${ }^{11}$. A 7-point Likert scale ranging from 1 
(disagree strongly) to 7 (agree strongly) and a middle position 4 (neutral/mixed) is used to score the items. Combined the two scales yield the attachment clusters defined by Bartholomew. The translation of the 36 items of the ECR in Dutch was done in two steps. First, a team consisting of the first author, a native English and fluent Dutch speaker, and a native Dutch with a degree in English, produced several translations in Dutch. Second, three psychologists with their main interest in attachment, including the first and second author, discussed the alternatives and made the final decisions about the translation.

\section{Statistical analyses}

Confirmative factor analysis was applied to examine the internal structure of the ECR in the three samples. We expected to replicate the two scale structure reported by Brennan et al. ${ }^{11}$. We applied the Multiple Group Method (MGM) ${ }^{13,14}$. Results generated by MGM are accurate and easy to inter$\operatorname{pret}^{15,16}$. In MGM the items are assigned to the theoretically expected subscales, in this case Avoidance and Anxiety. Adding up the different items that are expected to belong to the specific scale creates the subscales. The next step is to correlate each of the items with both subscales. When correlating an item with the subscale to which it is assigned, the problem of self-correlation arises. In that case not the correlation, but the item-rest correlation is computed. If each item has the highest correlation with the subscale to which it was assigned the proposed structure of the scales fits the data. An item is not rightly assigned to a subscale if it scores higher on another subscale than on the one to which it was assigned. In that case, the item should be reassigned to the other subscale.

Finally, internal consistencies (Cronbach's alphas) of the scales were computed and compared along the three samples, as well as the intercorrelations between the two subscales. We only analyzed those respondents who ever had experience with romantic relationships, because we think people without relationship experience can not complete the ECR properly.

\section{Results Study 1}

\section{Respondents}

Table I displays socio-demographic characteristics of the three samples and the general Dutch population. The two subsamples of Dutch students $(n=331$ in 2002, and $\mathrm{n}=366$ in 2003) were highly comparable on the socio-demographic variables, and therefore they were merged. Clearly, the American $(\mathrm{n}=1,012)$ and Dutch psychology student samples $(\mathrm{n}=697)$ show high resemblance. Concerning the Dutch population sample, a total of 233 booklets was returned, resulting in a satisfying response rate for this sampling method. From Table I we learn that sex ratio, mean age and civil status of our population sample are comparable with the general Dutch adult population. Mean level of education is skewed in the direction of higher education in our sample, which may be expected with our sampling method. Finally, mean relationship duration was far longer in the general population sample than in both the American and Dutch student samples, indicating more experience with lasting relationships.

Factor structure of the ECR, internal consistencies and intercorrelations

Tables IIa and IIb show the results of the MGM analysis, displaying the correlation coefficients between the individual items and both subscales. In general, all items correlate higher with the intended subscale than the other subscale. However, the mag- 
nitude of the (item-rest) correlations differs per sample.

Compared to the American student sample item-rest correlations of the intended Avoidance items (Table IIa) with the Avoidance subscale are obviously lower for item 29 in the Dutch student sample, and items 15 and again 29 in the Dutch population sample. Correlations of the a priori Avoidance items with the Anxiety subscale are somewhat higher in both Dutch samples, especially item 21 in the student sample and items 9, 11, 17 and 21 in the population sample compared to the American student sample. Item-rest correlations of the intended Anxiety items (Table IIb) with the Anxiety subscale are in general somewhat lower in both Dutch samples compared to the American student sample, especially item 10 in the Dutch student sample, and item 34 in the Dutch population sample. Correlations of the Anxiety items with the Avoidance subscale are in general somewhat higher in both Dutch samples compared with the American student sample, especially items 4, 6 and 26 in the Dutch population sample. When we look at the magnitude of the differences of the itemloadings on both subscales we can conclude that items 21 and 26 perform weakly in both Dutch samples compared with the American student sample.

Cronbach's alphas of Avoidance and Anxiety are resp.: .94 and .91 in the American student sample, .93 and .88 in the Dutch student sample, and .88 and .86 in the Dutch population sample. We computed Pearson's correlations between both subscales and found: .13 (American student sample), .14 (Dutch student sample), and .39 (Dutch population sample). All correlations are significant at $p$ $<.01$. Finally, mean and SD of Avoidance and Anxiety are resp.: 2.87 (1.14) and 3.45 (1.11) in the American student sample, 2.59 (.98) and $3.51(.88)$ in the Dutch student sample, and 2.49 (.91) and 3.09 (.97) in the Dutch population sample.

Table I

Socio-demographic characteristics.

\begin{tabular}{|c|c|c|c|c|}
\hline & $\begin{array}{l}\text { American student } \\
\text { sample } n=1,012\end{array}$ & $\begin{array}{c}\text { Dutch student } \\
\text { sample } n=697\end{array}$ & $\begin{array}{l}\text { Dutch population } \\
\text { sample } n=233\end{array}$ & $\begin{array}{c}\text { Dutch population } \\
20-80 \mathrm{yrs}^{1}\end{array}$ \\
\hline female & $62.8 \%$ & $75.6 \%$ & $46.2 \%$ & $50.3 \%$ \\
\hline mean age $(\mathrm{SD})$ & 19.3 yrs (3.2) & 21.3 yrs (6.2) & 48.4 yrs (16.6) & 45.0 yrs (n.a.) \\
\hline range & $16-50$ & 17.5-72.9 & $19-98$ & n.a. \\
\hline $\begin{array}{l}\text { civil status } \\
\text { unmarried }^{2} \\
\text { married } \\
\text { divorced } \\
\text { widow(er) }\end{array}$ & $\begin{array}{l}\text { n.a. } \\
\text { n.a. } \\
\text { n.a. } \\
\text { n.a. }\end{array}$ & $\begin{array}{l}\text { n.a. } \\
\text { n.a. } \\
\text { n.a. } \\
\text { n.a. }\end{array}$ & $\begin{array}{c}27.0 \% \\
57.9 \% \\
6.9 \% \\
8.2 \%\end{array}$ & $\begin{array}{c}27.6 \% \\
59.9 \% \\
7.5 \% \\
5.0 \%\end{array}$ \\
\hline mean relationship duration (SD) & 1.7 yrs (1.6) & $2.2 \operatorname{yrs}(3.3)$ & 19.5 yrs $(14.7)$ & n.a. \\
\hline range & $.00-15.00$ & $.83-27.83$ & $.08-65.8$ & n.a. \\
\hline $\begin{array}{l}\text { education } \\
\text { lower } \\
\text { middle } \\
\text { higher }\end{array}$ & $\begin{array}{c}- \\
100 \% \\
-\end{array}$ & $\begin{array}{c}- \\
100 \% \\
-\end{array}$ & $\begin{array}{c}20.6 \% \\
29.3 \% \\
50 \%\end{array}$ & $\begin{array}{l}35 \% \\
41 \% \\
24 \%\end{array}$ \\
\hline
\end{tabular}

${ }^{1}$ (CBS, 2001, SCP, 2001) CBS = Statistics Netherlands, SCP = Social and Cultural Planning Office of the Netherlands.

${ }^{2}$ Unmarried means single or cohabiting.

n.a. $=$ not available. 
Table IIa

Correlations of Avoidance items with both subscales.

\begin{tabular}{|c|c|c|c|c|c|c|}
\hline \multirow[b]{2}{*}{ Item } & \multicolumn{2}{|c|}{$\begin{array}{c}\text { American student } \\
\text { sample } \mathrm{n}= \pm 1,007\end{array}$} & \multicolumn{2}{|c|}{$\begin{array}{c}\text { Dutch student } \\
\text { sample } n= \pm 696\end{array}$} & \multicolumn{2}{|c|}{$\begin{array}{l}\text { Dutch population } \\
\text { sample } \mathrm{n}= \pm 227\end{array}$} \\
\hline & $\begin{array}{l}\text { Avoidance } \\
\text { (item-rest) }\end{array}$ & Anxiety & $\begin{array}{l}\text { Avoidance } \\
\text { (item-rest) }\end{array}$ & Anxiety & $\begin{array}{l}\text { Avoidance } \\
\text { (item-rest) }\end{array}$ & Anxiety \\
\hline 1 & .73 & .12 & .65 & -.01 & .40 & .19 \\
\hline 3 & .71 & .07 & .56 & .04 & .42 & .14 \\
\hline 5 & .71 & .12 & .66 & .11 & .63 & .30 \\
\hline 7 & .70 & .06 & .72 & .12 & .61 & .37 \\
\hline 9 & .69 & .14 & .76 & .20 & .60 & .46 \\
\hline 11 & .69 & .17 & .73 & .18 & .61 & .42 \\
\hline 13 & .68 & .07 & .71 & .14 & .62 & .28 \\
\hline 15 & .67 & .08 & .58 & .01 & .25 & -.08 \\
\hline 17 & .67 & .12 & .63 & .28 & .60 & .45 \\
\hline 19 & .67 & .10 & .58 & .12 & .50 & .25 \\
\hline 21 & .67 & .16 & .55 & .40 & .55 & .48 \\
\hline 23 & .66 & .03 & .71 & .04 & .58 & .26 \\
\hline 25 & .64 & .07 & .66 & -.02 & .45 & .06 \\
\hline 27 & .63 & .09 & .69 & .02 & .51 & .15 \\
\hline 29 & .64 & .08 & .36 & -.02 & .20 & -.07 \\
\hline 31 & .62 & .10 & .65 & .07 & .51 & .16 \\
\hline 33 & .63 & .04 & .55 & -.09 & .42 & .15 \\
\hline 35 & .60 & -.05 & .62 & -.07 & .62 & .04 \\
\hline
\end{tabular}

Table IIb

Correlations of Anxiety items with both subscales.

\begin{tabular}{|c|c|c|c|c|c|c|}
\hline \multirow[b]{2}{*}{ Item } & \multicolumn{2}{|c|}{$\begin{array}{c}\text { American student } \\
\text { sample } \mathrm{n}= \pm 1,007\end{array}$} & \multicolumn{2}{|c|}{$\begin{array}{c}\text { Dutch student } \\
\text { sample } \mathrm{n}= \pm 696\end{array}$} & \multicolumn{2}{|c|}{$\begin{array}{l}\text { Dutch population } \\
\text { sample } \mathrm{n}= \pm 227\end{array}$} \\
\hline & $\begin{array}{l}\text { Avoidance } \\
\text { (item-rest) }\end{array}$ & Anxiety & $\begin{array}{l}\text { Avoidance } \\
\text { (item-rest) }\end{array}$ & Anxiety & $\begin{array}{l}\text { Avoidance } \\
\text { (item-rest) }\end{array}$ & Anxiety \\
\hline 2 & .18 & .68 & .15 & .61 & .24 & .56 \\
\hline 4 & .18 & .65 & .31 & .53 & .45 & .53 \\
\hline 6 & .19 & .65 & .30 & .60 & .41 & .59 \\
\hline 8 & .18 & .63 & .16 & .68 & .26 & .54 \\
\hline 10 & .20 & .62 & -.06 & .23 & -.05 & .43 \\
\hline 12 & -.01 & .60 & .09 & .49 & .32 & .52 \\
\hline 14 & .12 & .60 & .10 & .55 & .10 & .45 \\
\hline 16 & .04 & .57 & .12 & .44 & .34 & .46 \\
\hline 18 & .08 & .57 & .13 & .51 & -.04 & .45 \\
\hline 20 & -.00 & .55 & .05 & .47 & .29 & .41 \\
\hline 22 & .11 & .55 & .13 & .62 & .19 & .38 \\
\hline 24 & .01 & .52 & -.03 & .46 & .31 & .50 \\
\hline 26 & .17 & .52 & .32 & .46 & .50 & .52 \\
\hline 28 & .11 & .51 & -.05 & .39 & .10 & .49 \\
\hline 30 & -.05 & .52 & .10 & .49 & .06 & .43 \\
\hline 32 & -.04 & .51 & .14 & .50 & .03 & .40 \\
\hline 34 & .01 & .51 & .10 & .42 & .17 & .33 \\
\hline 36 & .03 & .50 & .11 & .43 & .15 & .50 \\
\hline
\end{tabular}




\section{Discussion Study 1}

In general, we were able to replicate the original bi-dimensional structure of the ECR in both Dutch samples. The two factors emerged sharply in the Dutch psychology student sample and somewhat less clear but still satisfactorily recognizable in the Dutch population sample. In the latter sample, items tended to load more on both factors than in the Dutch student sample, resulting in a higher correlation between both subscales. Since we administered exactly the same version of the ECR in the Dutch student and population samples, this higher intercorrelation has to be due to sample variation. Moreover, because sample variation between the Dutch and American psychology student samples is small, and the intercorrelation between the subscales in both samples comparably low, we interpret this as an indication that the translation in general was successful. Furthermore, we think that the relatively minor differences in (item-rest) correlations between both Dutch samples and the American sample may be due to chance capitalization in the construction of the original version. However, a few items performed weakly in both Dutch samples, especially items 21 (I find it difficult to allow myself to depend on romantic partners) and 26 (I find that my partner(s) don't want to get as close as I would like). This is not attributable to sample variation, but could be due to a translation problem or cultural differences. Because of reasons of cross-national comparability we decided to leave the scales intact for investigation of the construct validity in Study 2. Finally, Cronbach's alphas were somewhat lower in both Dutch samples compared with the original American sample, but still high.

\section{Study 2: External validity}

\section{Introduction Study 2}

Because we wanted to shed some light on the external validity of the ECR, we correlated both scales with questionnaires measuring important attachment(-related) issues. First we shortly review research covering three of these issues, namely studies on: (1) convergent validity aspects of Avoidance and Anxiety; (2) attachment and relationship interaction; and (3) attachment and (vulnerability for) psychopathology.

To gain more insight in the core aspects, or the convergent validity, of the scales of the Dutch ECR, we included two other attachment measures in our study. First, we administered the Attachment Styles Questionnaire $(\mathrm{ASQ})^{17}$, because high correlations are reported in the original study ${ }^{11}$ between subscales of the ECR and ASQ. Avoidance correlates highly with Discomfort with Closeness (avoidance of attachment), and to a lesser extent with Relationships as Secondary to Achievement (self-protection against hurt and vulnerability by emphasizing achievement and independence). Anxiety correlates highly with Preoccupation with Relationships (anxious reaching out to others in order to fulfill dependency needs), and with Need for Approval (need for others' acceptance and confirmation). We expected to replicate these findings. Interestingly, the fifth subscale of the ASQ, Confidence (secure attachment), correlates in Brennan et al.'s study ${ }^{11}$ mainly with Avoidance, while it is described by Feeney and colleagues ${ }^{17}$ as a combination of Bartholomew's two working models. Because the scales of the ECR can be interpreted as those two working models, we expected Confidence to correlate more or less evenly with both Avoidance and Anxiety. 
Second, we also administered the Relationship Questionnaire (RQ) ${ }^{8}$, because it yields scores of Bartholomew's two working models. In the original American student sample, Avoidance and Anxiety correlate positively with the RQ's (negative) Models of Other and Self resp.

Next we paid attention to two important and closely related topics in adult romantic attachment research, i.e. accommodation strategies and relationship satisfaction. Accommodative behavior is the tendency of individuals to respond constructively to the destructive behavior of relationship partners, while inhibiting impulses to react destructively $^{18}$. Based on results of former research ${ }^{19,20}$ we expected Anxiety, and especially Avoidance to be negatively associated with constructive accommodation strategies and positively with destructive strategies.

Dissatisfaction with relationships is much stronger associated with avoidance of intimacy (or avoidance of emotional disclosure and partner proximity), than with fear of rejection or abandonment ${ }^{21,22}$. Therefore we expected a much higher correlation between relationship satisfaction and Avoidance, than with Anxiety.

Finally, we wanted to test associations between both attachment dimensions and (vulnerability for) psychopathology. Studies by Shaver and Brennan ${ }^{23}$ and Davis and Vernon $^{24}$, report moderate to high correlations between neuroticism and Anxiety, and low correlations with Avoidance. Studies on associations between the ECR and questionnaires measuring two highly prevalent forms of psychopathology, i.e. anxiety and depression, show similar patterns. Two studies in psychology student samples on the relation between anxiety symptoms and the ECR found correlations with Anxiety of .16 and .37 , and somewhat lower, .11 and .26, with
Avoidance $^{25}$. Several studies on associations between the ECR and depression measures in psychology student samples and adult samples, report correlations with Anxiety ranging from .40 to .56 , and with Avoidance from .10 to. $28^{22,25,26,27,28}$. Thus, both anxiety and depression correlate moderately with Anxiety and somewhat lower with Avoidance.

\section{Method Study 2}

\section{Respondents}

The three samples were the same as those reported in Study 1. The Dutch population sample completed all questionnaires described below, the American student sample only the attachment measures, and the Dutch students the ECR and, in one or the other of the two original subsamples, the Need for Approval and Discomfort with Closeness scales (ASQ) and scales measuring (vulnerability for) psychopathology.

\section{Measurement instruments}

A Dutch translation of the Attachment Styles Questionnaire ${ }^{17}$ was made following the same procedure as for the ECR. This self-report measures attachment within relations in general. It consists of 40 items scored on a 6-point Likert scale ranging from 1 (totally disagree) to 6 (totally agree), and five subscales already described in the introduction. Cronbach's alphas ranged from .76 to .84 in the present study.

The Relationship Questionnaire ${ }^{9}$, measuring attachment in general with significant others, was applied as well. The respondent rates four attachment style vignettes (Secure, Preoccupied, Fearful and Dismissing) on a 7-point Likert scale ranging from 1 (not at all characteristic for me) to 7 (totally characteristic for me). Model of 
Self- and Model of Other-scores are derived from combinations of the four ratings.

A Dutch version of The Accommodation Scale (AS) $)^{18}$, translated and adapted using the same procedure as with the ECR, was administered to measure accommodative behavior and interaction within romantic relationships. It measures proximity-promoting behavior or Constructive Strategies (actively attempting to resolve interpersonal problems, and/or passively waiting for conditions to improve), and proximity-rejecting behavior or Destructive Strategies (actively harming the relationship, and/or passively allowing conditions to deteriorate). The sixteen items are scored on a 9-point Likertscale ranging from 0 (I never do this) to 8 (I constantly do this). Cronbach's alphas are .78 for Constructive Accommodation, and .73 for Destructive Accommodation in this study.

We measured satisfaction with the current relationship with the Relational Interaction Satisfaction Scale (RISS) ${ }^{29}$. The seven items are scored on a Likert scale ranging from 1 (never) to 5 (always).

The Neuroticism scale of the NEO$\mathrm{FFI}^{30,31}$ was used to measure a personality based disposition for vulnerability for psychopathology. The twelve items are scored on a 5-point Likert scale ranging from 1 (totally disagree) to 5 (totally agree). To measure a comparable, but inversely formulated construct, the Emotional Stability scale of the Five-Factor Personality Inventory $(\mathrm{FFPI})^{32}$, was used. Its twenty items are scored on a 5-point Likert scale.

Finally, we measured general mental health, mainly anxiety- and depression-related problems with the General Health Questionnaire (GHQ-12) ${ }^{33,34}$. The twelve items are scored on a 4-point scale with values depending on the actual item, for example from 'not at all' to 'much more than usually'.

\section{Statistical analyses}

Pearson's correlations were computed to evaluate the formulated hypotheses. Like in Study 1 we only analyzed respondents who ever had experience with a romantic relationship.

\section{Results Study 2}

In general, Avoidance and Anxiety of the Dutch ECR correlate as may be expected from theory and former research described above (Table III). The scales of the ASQ correlate as predicted in all samples, although with lesser magnitude in both Dutch samples as compared to the American student sample. However, opposed to the American sample, Confidence correlates like we anticipated more evenly with both Avoidance and Anxiety in the Dutch population sample. With regard to Models of Other and Self, the correlations in the American student and the Dutch population samples are fairly comparable. Finally, concerning the relationship interaction variables, and (vulnerability for) psychopathology, Avoidance and Anxiety show correlations as predicted.

\section{Discussion Study 2}

With all our hypotheses supported by the results, we can draw the conclusion that the external validity of the Dutch ECR is clearly satisfying. This enables us to describe high scorers on both ECR dimensions. People with a high score on Avoidance have a negative model of others, experience discomfort with closeness, display a tendency for self-protection against hurt and vulnerability by emphasizing achievement and independence, lack attachment security, apply no constructive but destructive interaction strategies in 
their relationships, and experience low relational satisfaction. A high score on Anxiety suggests a negative model of self, a need for others' acceptance and confirmation, anxious reaching out to others in order to fulfill dependency needs, lack of attachment security, appliance of destructive interaction strategies in their relationships, vulnerability for psychopathology and higher symptomatology.

Table III

Correlations of Avoidance and Anxiety with several self-report scales.

\begin{tabular}{|c|c|c|}
\hline $\begin{array}{c}\text { American student } \\
\text { sample } \mathrm{n}=1,002 / 1,000\end{array}$ & $\begin{array}{l}\text { Dutch student } \\
\text { sample } \mathrm{n}={ }^{1-3}\end{array}$ & $\begin{array}{c}\text { Dutch population } \\
\text { sample } n=206 / 225\end{array}$ \\
\hline Avoidance & Avoidance Anxiety & Avoidance \\
\hline
\end{tabular}

\begin{tabular}{|c|c|c|c|c|c|c|}
\hline \multicolumn{7}{|l|}{ Attachment Styles Questionnaire } \\
\hline Need for Approval & $.23 * *$ & $.64 * *$ & $.36 * * 3$ & $.52 * * 3$ & $.23 * *$ & $.59 * *$ \\
\hline Preoccupation with Relation. & $.14 * *$ & $.88^{* *}$ & & & $.18^{* *}$ & $.66^{* * *}$ \\
\hline Discomfort with Closeness & $.88 * *$ & $.24 * *$ & $.58 * * 1$ & $.19 * * 1$ & $.49 * *$ & $.34 * *$ \\
\hline Relation. Sec. to Achievement & $.56 * *$ & $.17 * *$ & & & $.36^{* *}$ & $.24 * *$ \\
\hline Confidence & $-.68 * *$ & $-.27 * *$ & & & $-.36 * *$ & $-.37 * *$ \\
\hline \multicolumn{7}{|l|}{ Relationship Questionnaire } \\
\hline Negative Self Model & $.26 * *$ & $.55^{* *}$ & & & $.15^{*}$ & $.47 * *$ \\
\hline Negative Other Model & $.44^{* *}$ & -.05 & & & $.40 * *$ & $.18 * *$ \\
\hline \multicolumn{7}{|l|}{ Accommodation Scale } \\
\hline Constructive Accomm. Strat. & & & & & $-.30 * *$ & -.12 \\
\hline Destructive Accomm. Strat. & & & & & $.49 * *$ & $.40 * *$ \\
\hline Relation. Inter. Satisfaction & & & & & $-.62 * *$ & $-.36 * *$ \\
\hline Neuroticism (NEO-FFI) & & & $.27 * * 3$ & $.57 * * 3$ & $.27 * *$ & $.61 * *$ \\
\hline Emotional Stability (FFPI) & & & $-.05^{2}$ & $-.47 * * 2$ & & \\
\hline General Health Questionnaire & & & $.06^{2}$ & $.34 * * 2$ & $.21 * *$ & $.37 * *$ \\
\hline
\end{tabular}

Relation. Sec. to Achievement $=$ Relationship as Secondary to Achievement; Preoccupation with Relation. $=$ Preoccupation with Relationships; Constructive Accomm. Strat. = Constructive Accommodation Strategies; Destructive Accomm. Strat. $=$ Destructive Accommodation Strategies; Relation. Inter. Satisfaction $=$ Relational Interaction Satisfaction.

$* \mathrm{p}<.05, * * \mathrm{p}<.01$

1 Both students sub-samples: $\mathrm{n}=678$.

2 Sub-sample students 2002: Emotional Stability n $=256$; General Health Questionnaire $\mathrm{n}=296$.

3 Sub-sample students 2003: Need for Approval $n=354$; Neuroticism $n=357$.

\section{General Discussion}

The present study aimed at a psychometric evaluation of the Dutch ECR in comparison with the American version in the original sample. Because the original ECR was validated in a very homogeneous sample of psychology students, our second and third goals were to investigate the supposed orthogonality of the scales and to broaden the applicability of the ECR, by testing the questionnaire in a general population sample.
Compared with the original American version, the Dutch version of the ECR showed in general somewhat less strong psychometric qualities. However, this is predominantly due to sample differences as the MGM analyses showed. The Dutch psychology student sample yielded, reckoning with chance capitalization in the original sample, fairly similar results, with a comparable low correlation between the subscales. In the Dutch population sample both subscales were satisfactorily, but less clear, discernable, resulting in a higher correlation 
between both subscales. This finding is in contradiction with the claim of orthogonality of the ECR scales ${ }^{11}$. However, a short review of intercorrelations of both scales in several studies reveals that this claim is not empirically supported in general. In student and adult samples, intercorrelations vary considerably from .04 to $.30^{22,25,27,35}$, and from .08 to .56 for adapted versions of the $\mathrm{ECR}^{26,28}$. Hence, the higher intercorrelation in the Dutch population sample is not uncommon; and the higher the intercorrelation, the more variance items share with both subscales. Moreover, it should be noted, that Bowlby too did not expect orthogonality between the working models of self and other ${ }^{2}$.

Perhaps that in people with lasting relationships, like in our population sample, the avoidance and anxiety components of the attachment regulation system ${ }^{12}$ become more closely knit. The behavioral component of attachment, avoidance of intimacy, may for example become more a consequence of the emotional component of attachment, namely (anticipated) anxiety about rejection and abandonment. In this way the feedback between both attachment components can become stronger, and the intercorrelation higher.

Apart form the obvious role of sample variation, especially items 21 and 26 perform weakly in both Dutch samples. This may indicate a possible translation problem, or a phenomenon of cultural divergence. But because MGM analyses yielded good (student sample) to satisfactorily results (population sample), and because of reasons of comparability we decided to leave the scales intact. Moreover, the external validity of the subscales in the original 18 item version, including items 21 and 26, is clearly satisfying with all our hypotheses supported in both Dutch samples. Overall we can conclude that although orthogonality of the scales varies by sample, the support for the validity of the scales we found in both the student and the population samples warrants use of the ECR for research goals in more heterogeneous samples as well.

\section{Acknowledgements}

We gratefully thank Kelly Brennan for giving us permission to reanalyze the original data with which the ECR was validated.

\section{References}

1. Bowlby J. Attachment and loss: Vol. 1 Attachment. New York: Basic Books; 1969.

2. Bowlby J. Attachment and loss: Vol. 2 Separation. New York: Basic Books; 1973.

3. Bowlby J. The making and breaking of affectional bonds: I. Aetiology and psychopathology in the light of attachment theory. Br J Psychiatry 1977; 130: 201-210.

4. Bowlby J. Attachment and loss: Vol. 3 Sadness and depression. New York: Basic Books; 1980.

5. Hazan C, Shaver P. Romantic love conceptualized as an attachment process. J Pers Soc Psychol 1987; 52(3): 511524 .

6. Stein H, Jacobs NJ, Ferguson KS, Allen JG, Fonagy P. What do adult attachment scales measure? Bull Menninger Clin 1998; 6(1): 33-82.

7. Bartholomew K. Avoidance of intimacy: An attachment perspective. J Soc Pers Relat 1990; 7: 147-178.

8. Bartholomew K, Horowitz LM. Attachment styles among young adults: A test of a four-category model. J Pers Soc Psychol 1991; 61: 226-244.

9. Griffin DW, Bartholomew K. Models of self and other: Fundamental dimensions underlying adult attachment. J Pers Soc Psychol 1994; 67(3): 430-445.

10. Fraley RC, Spieker SJ. Are infant attachment patterns continuously or categorically distributed? A taxometric analysis of strange situation behavior. Dev Psychol 2003; 39: 387-404.

11. Brennan KA, Clark CL, Shaver PhR. Self-Report Measurement of Adult Attachment: An Integrative 
Overview. In: Simpson JA, Rholes WS, editors. Attachment theory and close relationships. New York: The Guilford Press; 1998. p. 46-76.

12. Fraley RC, Shaver PR. Adult romantic attachment: Theoretical developments. Rev Gen Psychol 2000; 4: 132154.

13.Guttman L. Multiple group methods for common-factor analysis: Their basis, computation and interpretation. Psychometrika 1952; 17: 209-222.

14. Nunnally JC. Psychometric theory. New York: McGraw-Hill; 1978.

15. Hendriks P, Kiers HAL. Confirmatory factor analysis methods compared: The multiple group method and maximum likelihood confirmatory factor analysis. Research report. Groningen: Department of Psychology; 1999.

16. Tuerlinckx F, Ten Berge JMF, Kiers HAL. Research report in Dutch: The multiple group method and confirmatory factor analysis with LISREL: A comparative study. Groningen: Department of Psychology; 1996.

17. Feeney JA, Noller P, Hanrahan M. Assessing adult attachment. In: Sperling MB, Berman WH et al., editors. Attachment in adults: Clinical and developmental perspectives. New York: The Guilford Press; 1994. p. 128-152.

18. Rusbult CE, Verette J, Whitney GA, Slovik LF, Lipkes I. Accommodation processes in close relationships: Theory and preliminary empirical evidence. J Pers Soc Psychol 1991; 60: 53-78.

19. Scharfe E, Bartholomew K. Accommodation and attachment representations in young couples. J Soc Pers Relat 1995; 12: 389-401.

20. Gaines SO, Reis HT, Summers S, Rusbult CE, Cox $\mathrm{CL}$, Wexler MO et al. Impact of attachment style on reactions to accommodative dilemmas in close relationships. Pers Relatsh 1997; 4: 93-113.

21. Frei JP, Shaver PR. Respect in close relationships: Prototype definition, self-report assessment, and initial correlates. Pers Relatsh 2002; 9: 121-139.

22. Shaver PhR, Schachner DA, Mikulincer M. Attachment style, excessive reassurance seeking, relationship processes and depression. Pers Soc Psychol Bull 2005; 3 : 343-359.

23. Shaver PR, Brennan KA. Attachment styles and the Big Five personality traits: Their connections with each other and with romantic relationship outcomes. Pers Soc Psychol Bull 1992; 18: 536-545.

24. Davis D, Vernon L. Sculpting the body beautiful: attachment style, Neuroticism, and use of cosmetic surgeries. Sex Roles 2002; 47: 129-138.

25. Williams NL, Riskind JH. Adult romantic attachment and cognitive vulnerabilities to anxiety and depression:
Examining the interpersonal basis of vulnerability models. $\mathrm{J}$ Cogn Psychother 2004; 18(1): 7-24.

26. Wei M, Mallinckrodt B, Larson LM, Zakalik RA. Adult attachment, depressive symptoms, and validation from self and others. J Couns Psychol 2005; 52: 368-377.

27. Whiffen VE. The role of partner characteristics in attachment insecurity and depressive symptoms. Pers Relatsh 2005; 12: 407-423.

28. Carmichael CL, Reis HT. Attachment, sleep quality and depressed affect. Health Psychol 2005; 24(5): 526-531.

29. Buunk BP. Relational Interaction Satisfaction Scale (RISS). In: Touliatos J, Perlmutter BF, Straus MA, editors. Handbook of Family Measurement Techniques. London: Saga Publications; 1990. p. 106.

30. Costa PT, McCrae RR. Revised NEO Personality Inventory (NEO PI-R) and NEO Five-Factor Inventory (NEO-FFI) professional manual. Odessa: Psychological Assessment Resources, Inc.; 1992.

31. Hoekstra HA, Ormel J, De Fruyt F. NEO PI-R - NEO FFI. Big Five Inventory. Manual. Lisse: Swets \& Zeitlinger; 1996.

32. Hendriks AAJ, Hofstee WKB, De Raad B, Angleitner A. The Five-Factor Personality Inventory (FFPI). Pers Individ Dif 1999; 27: 307-325.

33. Koeter MWJ, Ormel J. In Dutch: General Health Questionnaire. Dutch adaptation. Manual. Lisse: Swets \& Zeitlinger; 1991.

34. Oldehinkel AJ, Koeter MWJ, Ormel J, Hodiamont PPG, Sijben AES. In Dutch: Comparison of the GHQ-30 and the GHQ-12 as screening instruments for psychopathology. Tijdschrift voor Sociale Gezondheidszorg 1993; 71: 179-182.

35. Mallinckrodt B, Wei M. Attachment, social competencies, social support, and psychological distress. J Couns Psychol 2005; 52: 358-367.

Address for correspondence:

H.J. Conradi, M.Sc.

Department of Psychiatry

University Medical Center Groningen

P.O. Box 30.001

9700 RB Groningen

The Netherlands

tel: $+31-50-3614610$

fax: +31-50-361 9722

e-mail: h.j.conradi@med.umcg.nl

THE NETHERLANDS 